Results of intravenous tetracosactrin test $(500 \mathrm{mg}$ in $500 \% 5 \%$ dextrose) performed when patient was taking dexamethasone $0.5 \mathrm{mg}$ twice daily

\begin{tabular}{lc}
\hline $\begin{array}{l}\text { Time } \\
\text { (hours) }\end{array}$ & $\begin{array}{c}\text { Plasma cortisol } \\
\text { concentration } \\
(\text { nmol/l) }\end{array}$ \\
\hline 0 & 75 \\
1 & 346 \\
2 & 412 \\
3 & 421 \\
4 & 470 \\
5 & 479 \\
\hline
\end{tabular}

${ }^{\star}$ Expected maximum $>600 \mathrm{nmol} / \mathrm{l}$. deficiency. The high cortisol concentration during his first admission suggested that there was no deficiency in production of glucocorticoids, only in mineralocorticoids, although the suboptimal rise during infusion of tetracosactrin indicated some loss of reserve cortisol.

Postmortem studies have shown a high prevalence of adrenal disease in patients with AIDS. In one study of 41 subjects at necropsy $51 \%$ had cytomegalovirus adrenalitis. Hyponatraemia was the most common finding (in $75 \%$ ), although only two subjects had been suspected during life of having adrenal insufficiency. ${ }^{1}$ Stimulation with tetracosactrin may indicate impairment of adrenal function despite normal or high cortisol concentrations measured at random..$^{1-3}$

The cause of the adrenal dysfunction in our case is unknown; the dysfunction would probably have been overlooked if reliance had been placed on the raised cortisol concentration. We suggest that in patients with AIDS with lethargy, hypotension, hyponatraemia, or hyperkalaemia, deficiencies of mineralocorticoids and glucocorticoids should be investigated by measurement of aldosterone concentration and plasma renin activity; prolonged stimulation with tetracosactrin (intravenously or intramuscularly); and, perhaps, assay of serum adrenocorticotrophic hormone concentration when the serum cortisol concentration is normal or low.

Our findings suggest that some of the morbidity associated with AIDS is a result of mineralocortical deficiency. Adrenal complications caused by HIV are easily treated and should be considered in all patients with infections related to AIDS.

We thank Dr Louise Sugden for measuring plasma renin activity; Mrs Michelle Miller for measuring plasma aldosterone concentration; and Professor A Guz for permission to report this case.

1 Glasgow BJ, Steinsapir KD, Anders K, Layfield LJ. Adrenal pathology in the acquired immune deficiency syndrome. Am f Clin Pathol 1985;84:594-7.

2 Membreno L, Irony I, Dere W, Klein R, Biglieri EG, Cobb E. Adrenocortical function in acquired immunodeficiency syndrome. $\mathcal{F}$ Clin Endocrinol Metab 1987;65:482-7.

3 Greene LW, Cole W, Greene JB, et al. Adrenal insufficiency as a complication of the acquired immunodeficiency syndrome. Ann Intern Med 1984;101:497-8.

(Accepted 14 November 1988)

\section{Assessing glycaemic control in non-insulin dependent diabetes: acceptability of blood sampling at home}

\author{
Alice Tippetts, PaulCallaway, Brian Leatherdale, \\ David Rowe
}

Department of Diabetes and Endocrinology, Royal South Hants Hospital, Southampton SO9 4PE Alice Tippetts, medical student

Paul Callaway, MRCP, research registrar

Brian Leatherdale, FRCP, consultant physician

\section{Department of Chemical Pathology, Southampton General Hospital, Southampton \\ David Rowe, MRCPATH, top grade biochemist}

Correspondence to: Dr Callaway.

BrMed f 1989;298:497-8
Measurement of glycosylated haemoglobin concentration is an accurate and convenient method of assessing overall glycaemic control in diabetes but is expensive and labour intensive.' In non-insulin dependent diabetes fasting blood glucose concentration correlates well with glycosylated haemoglobin concentration and is much cheaper to measure. ${ }^{2}$ In our hospital patients are therefore asked to have their fasting blood glucose concentration estimated before their visit to the clinic. This requires patients to make a visit to the laboratory while fasting.

We studied the acceptability and relative costs of three methods of obtaining samples for measuring fasting glucose concentration: by venepuncture in the laboratory and by finger pricking at home to produce blood spots on filter paper and reagent strips (BM 1-44; Boehringer Mannheim). Blood spots on filter paper have been used in previous studies, ${ }^{34}$ but their acceptability to patients is not known.

\section{Patients, methods, and results}

Sixty eight non-insulin dependent diabetics who did not regularly monitor their blood glucose concentrations at home agreed to produce blood spots and use reagent strips at home after fasting. All received oral and written instructions on performing the tests from one investigator. Samples were enclosed in plastic bags and returned in envelopes to the laboratory.

We analysed blood spots, which are stable at room temperature for eight days, by the method described by Gamlen et al.5 The results correlated well with venous blood glucose concentrations measured with a Yellow Springs analyser $(r=0.977 ; \mathrm{p}<0.001 ; n=56)$. Values obtained with reagent strips read with a reflectance meter at the time of sampling $(r=0.909$; $\mathrm{p}<0.001 ; \mathrm{n}=45$ ) and after postal delivery to the clinic $(\mathrm{r}=0.900 ; \mathrm{p}<0.001 ; \mathrm{n}=45)$ also correlated well with venous concentrations.

Fifty patients returned both "blood tests, and one patient returned only the blood spot. There were no significant differences in age, sex, or duration of diabetes between respondents and non-respondents. Four of the 10 patients who had used reagent strips before produced inadequate strips (Fisher's exact test $\mathrm{p}=0.043$ ), although all produced adequate blood spots. Patients with no experience of finger pricking produced significantly better spots than strips (table).

Adequacy of reagent strips and blood spots on filter paper produced by 40 patients with no experience of finger pricking $\star$

\begin{tabular}{lccc}
\hline & \multicolumn{3}{c}{ Spots } \\
\cline { 2 - 4 } Reagent strips & Adequate & Inadequate & Total \\
\hline Adequate & 14 & 8 & 14 \\
Inadequate & 18 & 8 & 40
\end{tabular}

McNemar's test statistic (with Yates's correction) $=\mathbf{1 6} \cdot \mathbf{0 5}, \mathrm{p}<\mathbf{0} \cdot 0005$

*Reagent strips were considered inadequate if blood was smeared or did not * Reagent strips were considered inadequate if blood was smeared or did not cover the whole colour block, or if they could not be read by a reflectance
meter. Filter paper spots were considered inadequate if blood had not meter. Filter paper spots were considered inadequate
soaked through the filter paper to a diameter of $6 \mathrm{~mm}$.

Patients who produced adequate strips were on average younger (mean (SD) age $57 \cdot 4(14 \cdot 1)$ years) than those who produced inadequate strips $(65 \cdot 6(9 \cdot 2))$ $(\mathrm{p}=0.033)$. This was also true for spots $(61.3(12 \cdot 4) v$ $67 \cdot 3(7 \cdot 2)$ years, $p=0 \cdot 033)$.

Fifty one patients, 47 of whom had returned samples, later returned a questionnaire. Eighteen found visits for laboratory sampling inconvenient. Of the 45 who stated preferences, 31 preferred home sampling to venepuncture at the laboratory or the general practitioner's surgery. Preference was not significantly related to age, sex, or duration of diabetes.

With information from the questionnaire and the laboratory we estimated costs of materials and technicians' time and costs to patients of the three methods of sampling; blood spots had to be posted to the laboratory, whereas patients took reagent strips to the clinic to be read by a reflectance meter. Sampling at the hospital was most expensive for both the NHS 
$(68 p)$ and the patient $(80 p)$. The two home tests were of comparable cost to the NHS (49p for blood spots, $45 p$ for strips). Costs of materials for all three methods were similar (20p). Blood spots cost the patient $19 p$ in postage, but strips brought to the clinic did not cost the patient anything.

\section{Comment}

The results show a strong preference for home testing, although most patients had no experience of finger pricking. Many patients found the visit to the laboratory after fasting inconvenient. Patients produced significantly better blood spots than reagent strips, probably because it requires more practice to produce satisfactory strips.

We conclude that patients find producing blood spots on filter paper or reagent strips at home and sending them by post before clinical review to be an attractive method of measuring fasting glucose concentration and cheaper than attending a laboratory.

PC was funded by Boehringer Mannheim. We thank Mr John Williams for statistical advice and Miss J Matthews for secretarial help.

1 Gabbay KH, Hasty K, Breslow JL, Ellison RC, Bunn HF, Gallop PM Glycosylated haemoglobins and long-term blood glucose control in diabetes mellitus. F Clin Endocrinol Metab 1977;44:859-64.

Muir A, Howe-Davies SA, Turner RC. General practice care of non-insulindependent diabetes with fasting blood glucose measurements. $A m \mathcal{F}$ Med 1982;73:637-40.

3 Wakelin K, Goldie DJ, Hartog M, Robinson AP. Measurement of capillary blood glucose in filter-paper spots: an aid to the assessment of diabetic control. Br Med f 1978-ii:468-9.

4 Paisey R, Bradshaw P, Hartog M, West P. Home monitoring of blood glucose using filter paper strips. Br Med f 1979;ii: 1509.

5 Gamlen TR, James HC, Batstone GF. The determination of blood spot glucose concentration using a rapid kinetic assay. Scand J Clin Lab Invest 1982;42. 643-5.

(Accepted 7 November 1988)

\section{Waldenström's macroglobulinaemia: three cases in shoe repairers}

\section{Lorna M Williamson, Michael Greaves, Jonathan R Waters, C C Harling}

\section{Department of \\ Haematology, Royal \\ Hallamshire Hospital, \\ Sheffield S10 2JF \\ Lorna M Williamson, MD, senior registrar \\ Michael Greaves, FRCP senior lecturer and consultant \\ Department of \\ Occupational Health, \\ Northern General \\ Hospital, Sheffield S5 7AU \\ Jonathan R Worters, MRCP, locum senior registrar \\ C C Harling, MFOM, consultant}

Correspondence to: Dr L M Williamson, Regional

Transfusion and

Immunohaematology

Centre, Cambridge

CB2 2PT.

BrMed f 1989;298:498-9 as shoe repairers.

\section{Case histories}

Waldenström's macroglobulinaemia is an uncommon, low grade lymphoproliferative malignancy of the elderly characterised by infiltration of the bone marrow by plasmacytoid lymphocytes and high serum concentrations of IgM paraprotein, causing hyperviscosity. Its cause is unknown, and no risk factors for its development have been described. We were surprised to find that, of six patients with Waldenström's macroglobulinaemia, three had worked for long periods

The three patients were men aged 64,57 , and 83 respectively at presentation. All fulfilled the diagnostic criteria for Waldenström's macroglobulinaemia - that is, they had extensive infiltration of the bone marrow and a high plasma monoclonal IgM $x$ concentration (table). All three developed mucosal bleeding, and in cases 1 and 2 the abnormalities of coagulation were consistent with those in von Willebrand's disease, which is a rare complication of paraproteinaemia. Coagulation returned to normal after treatment with cyclophosphamide.

All three patients had worked for more than 40 years in family shoe repairing businesses and had been exposed to leather, rubber adhesives, dyes, and paints. None of them had taken any specific protective precautions, though modern finishing machines contain extractor fans, and they had not monitored dust and solvent levels. Furthermore, two of them had lived

Details of three shoe repairers with Waldenström's macroglobulinaemia

\begin{tabular}{|c|c|c|c|c|c|c|}
\hline \multirow{2}{*}{$\begin{array}{l}\text { Case } \\
\text { No }\end{array}$} & \multirow{2}{*}{$\begin{array}{c}\text { Serum } \\
\mathrm{IgM} \\
(\mathrm{g} / \mathrm{l})^{\star}\end{array}$} & \multicolumn{2}{|c|}{ Kaolin cephalin clotting time (seconds) } & \multirow{2}{*}{$\begin{array}{c}\text { Factor VIII } \\
\text { (coagulant activity) } \\
(\text { IUU/l) } \dagger\end{array}$} & \multirow{2}{*}{$\begin{array}{c}\text { Factor VIII } \\
\text { (ristocetin cofactor) } \\
\text { (IU/l) } \dagger\end{array}$} & \multirow{2}{*}{$\begin{array}{c}\text { Factor VIII } \\
\text { (von Willebrand factor) } \\
(\text { IU/l) } \dagger\end{array}$} \\
\hline & & In patient & Control value & & & \\
\hline 1 & 54 & 56 & 41 & 350 & 400 & 180 \\
\hline 2 & 55 & 55 & 39 & 370 & 160 & 190 \\
\hline 3 & 54 & 41 & 39 & NA & NA & NA \\
\hline
\end{tabular}

Normal range $=0.5-2.0 \mathrm{~g} / \mathrm{l}$

tNormal range for all three VIII components $=500-1500$ IU/

$\mathrm{NA}=$ Not available. above their shops, and one stated that when the fumes in the shop became excessive the door leading to the living quarters was opened to clear the air.

\section{Comment}

Our patients were exposed to leather and rubber dust when cutting and buffing soles and heels, which were previously made from natural rubber and are now made from synthetic, vulcanised styrene-butadiene rubber. Before the second world war the adhesive used in shoe repairing was natural rubber solution, consisting of natural rubber dissolved in petroleum naphthas such as benzene, alkylbenzenes, and paraffins. Cellulose cement softened with amyl acetate was also used. Synthetic rubber cements consisting of polychloroprene (Neoprene) or polyurethane dissolved in organic solvents have been used since the 1950s. Shoe dyes were often alcohol based-for example, nigrosine black.

In 1985 Waldenström's macroglobulinaemia was mentioned in 117 death certificates in England and W.ales (population 49.9 million), ${ }^{1}$ giving a potential death rate of $1 / 430000$ a year. In the year 1984-5 the Leukaemia Research Fund's centre for clinical epidemiology registered 98 new cases (59 men and 39 women) from a population base of 20 million, giving an incidence of about 1/200000 a year (R A Cartwright, personal communication). The $10 \%$ sample of the 1981 census recorded 530 shoe repairers in Great Britain (Office of Population Censuses and Surveys, unpublished data), of whom 106 were in the 55-64 age group. Thus the number of elderly and retired shoe repairers in the catchment population of 300000 from which our three patients came would be unlikely to be more than 20. Thus the observed incidence of Waldenström's macroglobulinaemia among shoe repairers in the Sheffield area is many times greater than expected.

Because the calculated death rate from Waldenström's macroglobulinaemia is of the same order of 